\title{
Investigation of laser-induced ablation of ceramic materials for space- borne applications
}

\author{
H. Schroeder ${ }^{1, *}$, M. Hippler ${ }^{1}$, P. Allenspacher ${ }^{1}$, W. Riede ${ }^{1}$, A. Ciapponi ${ }^{2}$, \\ A.B. Mateo ${ }^{2}$, T. Ivanov' ${ }^{2}$ J. Alves ${ }^{2}$, J. Piris ${ }^{2}$, C. Heese ${ }^{2}$, D. Wernham ${ }^{2}$ \\ ${ }^{1}$ German Aerospace Center, Stuttgart, Germany \\ ${ }^{2}$ ESA-ESTEC, Noordwijk, The Netherlands
}

\begin{abstract}
In this work tests for determination of ablation thresholds of various ceramic materials for pulsed laser irradiations at wavelengths of $355 \mathrm{~nm}$ and $1064 \mathrm{~nm}$ in vacuum are presented. For comparison tests with copper and aluminium are also reported. The ablation process was monitored insitu by long-distance microscopy. The morphology of ablation spots was exsitu inspected by scanning electron microscopy. Furthermore, the redeposition of potentially released particles on optics in the vicinity to the target was examined.
\end{abstract}

Keywords: pulsed laser-induced ablation, ceramic materials, ablation threshold, space-borne lasers

\section{INTRODUCTION}

Complex laser systems are increasingly used in space missions e.g. for ranging, topographical mapping of planetary surfaces, and for monitoring Earth's atmosphere. Corresponding space-borne laser systems have to meet stringent requirements concerning reliability, precision, lifetime and damage threshold of optical components [1,2,3]. This applies not only to coatings and substrate materials of optics but also to beam dumps, pinholes and apertures. These elements typically consist of metallic or ceramic materials and they should have a high ablation threshold. Otherwise, emitted particles or molecules will redeposit on optical components of the system and deteriorate their functionality. For simulation of space conditions all reported experiments were performed under vacuum.

\section{EXPERIMENTAL SETUPS AND TEST PROCEDURES}

\subsection{Determination of ablation thresholds}

A schematic of the test setup is shown in figure 1. Main part is a stainless steel vacuum chamber in spherical shape with a diameter of $15 \mathrm{~cm}$. The flanges are sealed by copper gaskets (Conflat). The pumping system consists of a turbomolecular pump and an oilfree scroll pump. All tests were performed at a pressure below $10^{-6}$ mbar in order to simulate space conditions. The sample is mounted in the center of the vacuum chamber on a z-translation stage. This allows to run several tests on each sample on different positions without breaking the vacuum.

The laser source consists of a diode pumped, Q-switched master oscillator and a dual rod, single flashlamp pumped amplifier stage in dual pass operation. It delivers a single longitudinal mode laser beam at a wavelength of $1064 \mathrm{~nm}$ with 3 ns pulse duration (FWHM (full width at half maximum)). Pulse repetition rate is $100 \mathrm{~Hz}$. For the tests at $355 \mathrm{~nm}$ the IR laser light is frequency converted by two KD*P crystals. The laser system is operated at constant power to ensure stable

* helmut.schroeder@dlr.de; www.dlr.de/tp

Laser-Induced Damage in Optical Materials 2016, edited by Gregory J. Exarhos, Vitaly E. Gruzdev,

Joseph A. Menapace, Detlev Ristau, MJ Soileau, Proc. of SPIE Vol. 10014, 100141K

(c) 2016 SPIE · CCC code: 0277-786X/16/\$18 - doi: 10.1117/12.2244507 
output power and beam profile. Pulse energy variation is realized by an external attenuator with halfwave plate and thin film polarizer.

By a wedge a small part of the beam is outcoupled for online monitoring of the pulse energy and beam profile measurement. The energy detector is calibrated prior to the test by a simultaneous measurement of the effective pulse energy in front of the entrance window. The laser beam is focused by a plano-convex lens with a focal length of $75 \mathrm{~cm}$ onto the sample. Typical beam diameter is $200 \mu \mathrm{m}$. The sample is oriented at $45^{\circ}$ with respect to the beam direction. The beam profile is measured with a CCD camera on a sample equivalent position. Peak fluence values $F_{\text {peak }}$ are calculated using the following equation: $\mathrm{F}_{\text {peak }}=2 * \mathrm{E}_{\text {pulse }}{ }^{*} \cos \alpha / \pi^{*} \mathrm{r}_{\mathrm{x}}{ }^{*} \mathrm{r}_{\mathrm{y}}$. $\mathrm{E}_{\text {pulse }}$ is the pulse energy, $\mathrm{r}_{\mathrm{x}, \mathrm{y}}$ are the beam radii in $\mathrm{x}$ and $\mathrm{y}$ direction and $\alpha$ is the angle of incidence $\left(45^{\circ}\right)$.

For precise determination of ablation thresholds it is essential to monitor even small changes on the surface of the samples preferably online during the irradiation. To this end a long-distance microscope (LDM) with MaksutovCassegrain catadioptric design was used in combination with a CCD camera. The optical resolution of this system is better than $10 \mu \mathrm{m}$. The LDM is perpendicularly aligned with the surface of the samples.

Ablation thresholds were determined in tests with $30 \mathrm{k}$ shots. Starting from high values the peak fluence was step-bystep decreased until no change on the surface was observable by LDM monitoring. The online observations were validated by exsitu scanning electron microscopy (SEM). Fig. 2 shows online recorded LDM micrographs in dependence on shot number for a test with $\mathrm{Si}_{3} \mathrm{~N}_{4}$ at a fluence above ablation threshold. For comparison an exsitu taken SEM picture for a $30 \mathrm{k}$ shot test is also shown.

Besides the above mentioned $30 \mathrm{k}$ shot tests, additional, 1-hour tests (1.1 M shots) were run at a peak fluence $10 \%$ below the ablation threshold.

Following ceramic materials were tested: aluminium oxide $\left(\mathrm{Al}_{2} \mathrm{O}_{3}\right)$, boron nitride $(\mathrm{BN})$, aluminium nitride (AlN), silicon carbide (SiC), zirconium dioxide $\left(\mathrm{ZrO}_{2}\right)$, tungsten carbide (WC), silicon nitride $\left(\mathrm{Si}_{3} \mathrm{~N}_{4}\right)$, and Macor. Macor was involved into the investigations, due to its easy machinability with standard tools. Macor is a glass ceramic and it is composed of the following components: silicon dioxide (46\%), magnesium oxide (17\%), aluminium oxide (16\%), potassium oxide (10\%), boron trioxide (7\%), and fluorine (4\%). For comparison, tests with two metals (copper and aluminium) were also performed. In table 1 all tested materials are listed, together with density and thermal properties. For the tests discs with 1 inch diameter were used. Prior to the tests all samples were baked out at $500^{\circ} \mathrm{C}$ for four hours at ambient air in order to remove potential contaminations in particular organic residuals. In case of Macor comparitive tests at $355 \mathrm{~nm}$ were run with unbaked samples.

Table 1: Compilation of tested materials indicating their thermomechanical properties $\left({ }^{1}\right.$ maximum recommended service temperature, ${ }^{2}$ decomposition, ${ }^{3}$ sublimation). The data given are manufacturer specifications (Corning Inc.; Ceratec NTK Co.). Data for Cu and Al retrieved from [4].

\begin{tabular}{|l|l|l|l|l|l|l|l|l|l|l|l|}
\hline & Macor & $\mathrm{Al}_{2} \mathrm{O}_{3}$ & $\mathrm{BN}$ & $\mathrm{AIN}$ & $\mathrm{SiC}$ & $\mathrm{ZrO}_{2}$ & $\mathrm{WC}$ & $\mathrm{Si}_{3} \mathrm{~N}_{4}$ & & $\mathrm{Cu}$ & $\mathrm{Al}$ \\
\hline $\begin{array}{l}\text { Density } \\
{\left[\mathrm{g} / \mathrm{cm}^{3}\right]}\end{array}$ & 2.52 & 3.9 & 2.1 & 3.3 & 3.1 & 6.1 & 15.6 & 3.3 & 8.96 & 2.7 \\
\hline $\begin{array}{l}\text { Melting } \\
\text { point [ }\end{array}$ & $\mathbf{1 3 0 0}^{1}$ & 2050 & 2700 & 2200 & $>2300^{2}$ & 2680 & 2785 & $1900^{3}$ & 1085 & 659 \\
\hline $\begin{array}{l}\text { Thermal } \\
\text { conductivity } \\
\text { [W/mK] }\end{array}$ & 1.5 & 30 & 20 & 180 & 110 & 2.5 & 110 & 35 & 400 & 236 \\
\hline $\begin{array}{l}\text { Specific heat } \\
{[\mathrm{J} / \mathrm{kgK}]}\end{array}$ & 790 & 880 & 795 & 1045 & 625 & 420 & 945 & 700 & 385 & 895 \\
\hline
\end{tabular}




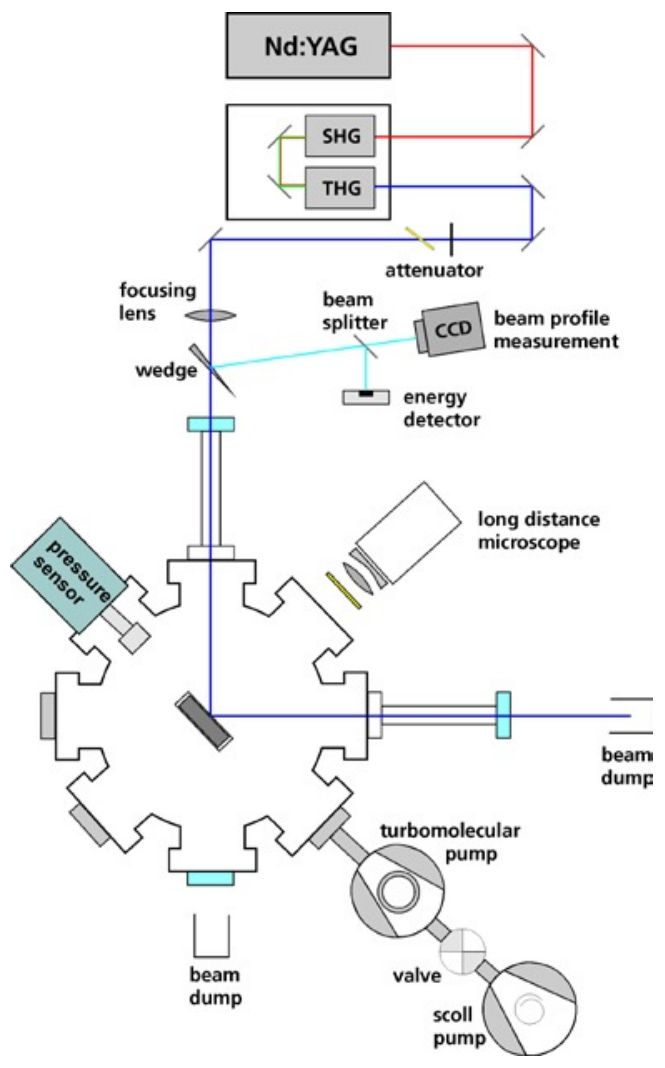

Figure 1: Scheme of set-up for determination of ablation thresholds.
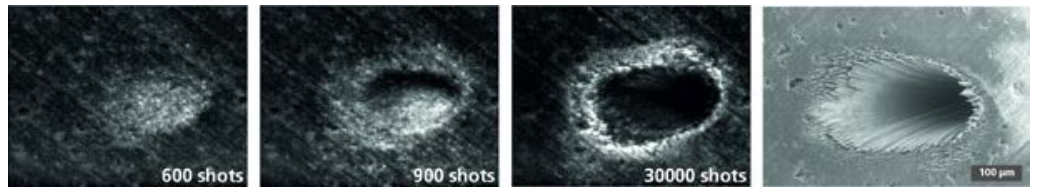

Figure 2: Online taken LDM pictures in dependence of laser pulse number and ex-situ taken SEM micrograph (Target: $\mathrm{Si}_{3} \mathrm{~N}_{4}, 355 \mathrm{~nm}$, peak fluence: $5 \mathrm{~J} / \mathrm{cm}^{2}$ )

\subsection{Particle emission}

The setup which was used for evaluation of particle emission is shown schematically in fig. 3. It consists of a vacuum chamber with oilfree pumping system. The entrance window for the laser beam served also as witness sample. The ceramic sample to be tested was placed $1.3 \mathrm{~cm}$ apart from the witness sample inside the vacuum chamber. The witness sample was uncoated fused silica.

For these tests the third harmonic ( $355 \mathrm{~nm}$ ) of an unseeded pulsed Nd:YAG laser was used. The repetition rate was 100 $\mathrm{Hz}$ and the pulse width $3.8 \mathrm{~ns}$ (FWHM). The tests were performed at room temperature and at a pressure below $10^{-2}$ mbar. Each sample was irradiated with 5 Mshots. This corresponds to an irradiation time of appr. $14 \mathrm{~h} \mathrm{at} 100 \mathrm{~Hz}$. The tested samples (Macor, $\mathrm{Al}_{2} \mathrm{O}_{3}, \mathrm{BN}$, AlN, and WC) were the same which were already used for the tests mentioned above for evaluation of ablation thresholds. On each sample two tests were performed, one with a peak fluence in the range of the ablation threshold and one with a fluence value four times lower. 
The witness samples were inspected before and after the irradiation for released particles from the ceramic sample by means of white light interference microscopy (WLIM), bright-field microscopy, transmission mapping, and SEM inclusive of energy dispersive X-ray spectroscopy (EDX). Prior to the tests with the ceramic samples blank tests without target were performed and the witness samples were inspected for reference.

The results will determine whether released particles from the ceramic sample adhere to the witness optical sample during laser operation at vacuum conditions.

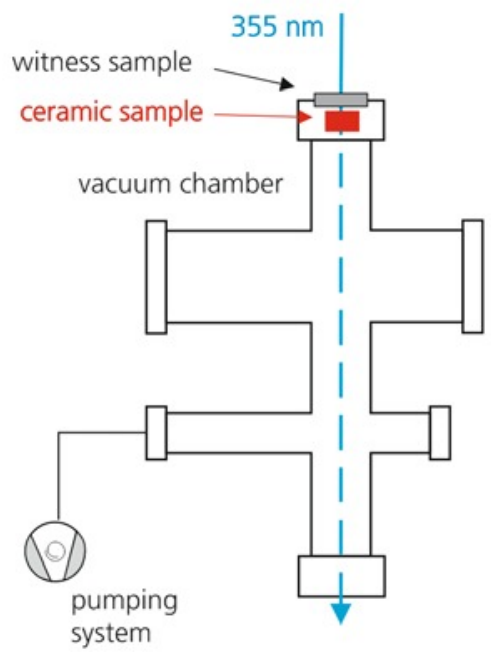

Figure 3: Scheme of set-up for investigation of particle emission and redeposition

\section{RESULTS}

\subsection{Ablation thresholds}

In table 2 and figure 4 the ablation thresholds, evaluated from the tests with $355 \mathrm{~nm}$ and $1064 \mathrm{~nm}$ are compiled. For both wavelengths Macor and $\mathrm{Al}_{2} \mathrm{O}_{3}$ show the highest values compared to the other ceramic materials but also with respect to metals. Especially for $1064 \mathrm{~nm}$ the values for Macor are considerably higher than for the other materials. The morphology of the ablation spots was investigated by SEM inspection (figures 5-9). Direct comparison of ablation spots on Macor and $\mathrm{Al}_{2} \mathrm{O}_{3}$ demonstrates the superior behaviour of Macor.

Looking at the thermal parameters and the density, no unambiguous correlation to the ablation thresholds was found. Obviously, other material properties (absorption coefficient, reflectivity, as well as geometric properties (homogeneity, surface morphology, etc.) may have great influence on the ablation behaviour.

Comparitive tests with baked and non baked Macor showed no difference in ablation thresholds. But for non baked Macor it was found, that during irradiations a dark ring was formed around the ablation spot. Outside this ring, the surface showed strong fluorescence. Even for a test run at $0.5 \mathrm{~J} / \mathrm{cm}^{2}$, i.e. below ablation threshold, considerable fluorescence at the spot position was observed. This indicates the presence of organic compounds. For the baked material no ring and significant fewer fluorescence was observed (figure 10). Probably, the bake out has removed organic residuals from the surface of the sample. 
In long term tests, which were run with peak fluence values app. 10\% below prior determined ablation thresholds in $30 \mathrm{k}$ shot tests no change of the surface was detectable, neither by on-line microscopy nor by ex-situ SEM inspection. Maximum magnification for recorded SEM micrographs was 1000.

Table 2: Ablation thresholds for pulsed laser irradiations at 355 and $1064 \mathrm{~nm}$.

\begin{tabular}{|l|c|c|}
\hline & $\begin{array}{c}\text { Ablation threshold } \\
@ \mathbf{3 5 5} \mathbf{~ n m} /\left[\mathbf{J} / \mathbf{c m}^{2}\right]\end{array}$ & $\begin{array}{c}\text { Ablation threshold } \\
@ \mathbf{1 0 6 4} \mathbf{~ n m} /\left[\mathbf{J} / \mathbf{c m}^{2}\right]\end{array}$ \\
\hline $\mathbf{M a c o r}$ & $1.7 \pm 0.3$ & $19 \pm 4$ \\
\hline $\mathbf{A l}_{\mathbf{2}} \mathbf{O}_{3}$ & $1.2 \pm 0.2$ & $8 \pm 2$ \\
\hline $\mathbf{S i C}$ & $0.7 \pm 0.1$ & $1.5 \pm 0.3$ \\
\hline $\mathbf{A l N}$ & $0.6 \pm 0.1$ & $1.6 \pm 0.3$ \\
\hline $\mathbf{Z r O} \mathbf{2}_{2}$ & $0.6 \pm 0.1$ & $1.1 \pm 0.2$ \\
\hline $\mathbf{B N}$ & $0.5 \pm 0.1$ & $2.8 \pm 0.6$ \\
\hline $\mathbf{S i}_{3} \mathbf{N}_{\mathbf{4}}$ & $0.4 \pm 0.1$ & $0.6 \pm 0.1$ \\
\hline $\mathbf{W C}$ & $0.3 \pm 0.1$ & $1.1 \pm 0.2$ \\
\hline & & \\
\hline $\mathbf{A l}$ & $0.8 \pm 0.1$ & $1.5 \pm 1.1$ \\
\hline $\mathbf{C u}$ & $0.3 \pm 0.1$ & $5.4 \pm 0.3$ \\
\hline
\end{tabular}
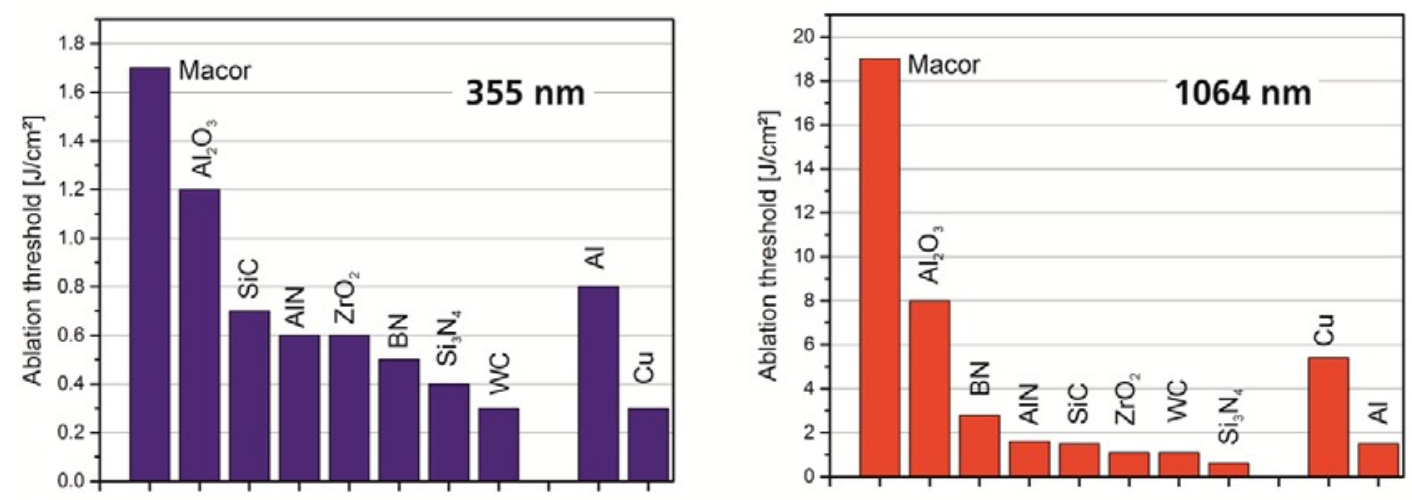

Figure 4: Ablation thresholds for pulsed laser irradiations at 355 and $1064 \mathrm{~nm}$.
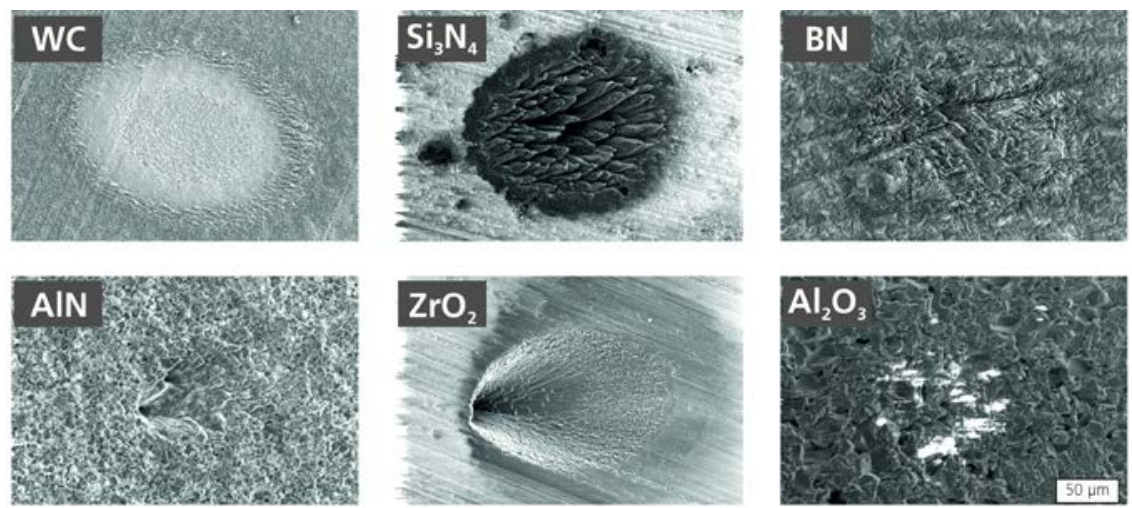

Figure 5: SEM micrographs of ablation spots after $30 \mathrm{k}$ shots irradiations at $355 \mathrm{~nm}$ with peak fluence of $0.85 \mathrm{~J} / \mathrm{cm}^{2}$. 

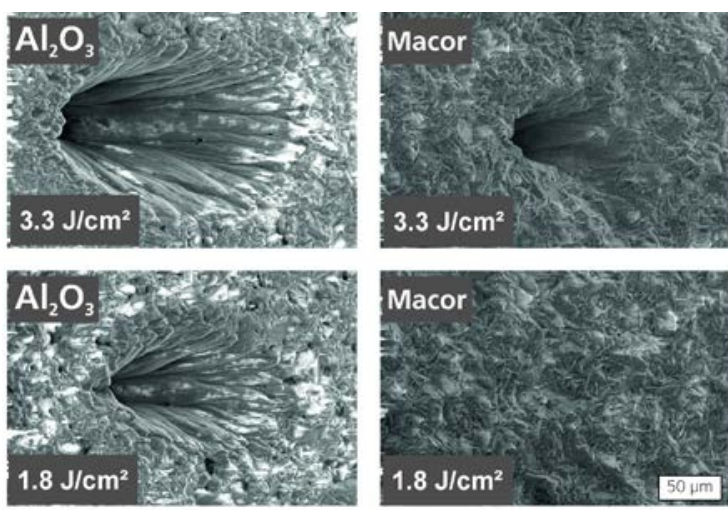

Figure 6: Comparison of ablation spots on $\mathrm{Al}_{2} \mathrm{O}_{3}$ and Macor after irradiations at $355 \mathrm{~nm}$ (30 k shots).
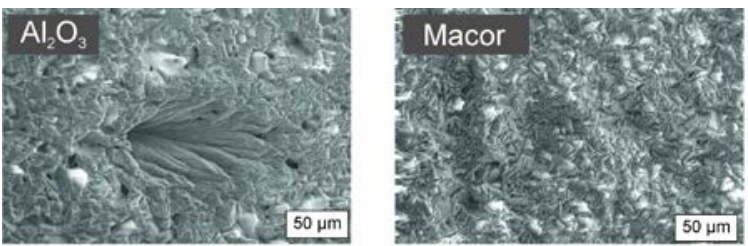

Figure 7: Comparison of ablation spots on $\mathrm{Al}_{2} \mathrm{O}_{3}$ and Macor after long term tests ( $355 \mathrm{~nm}, 1.4 \mathrm{~J} / \mathrm{cm}^{2}, 1.1 \times 10^{6}$ shots).
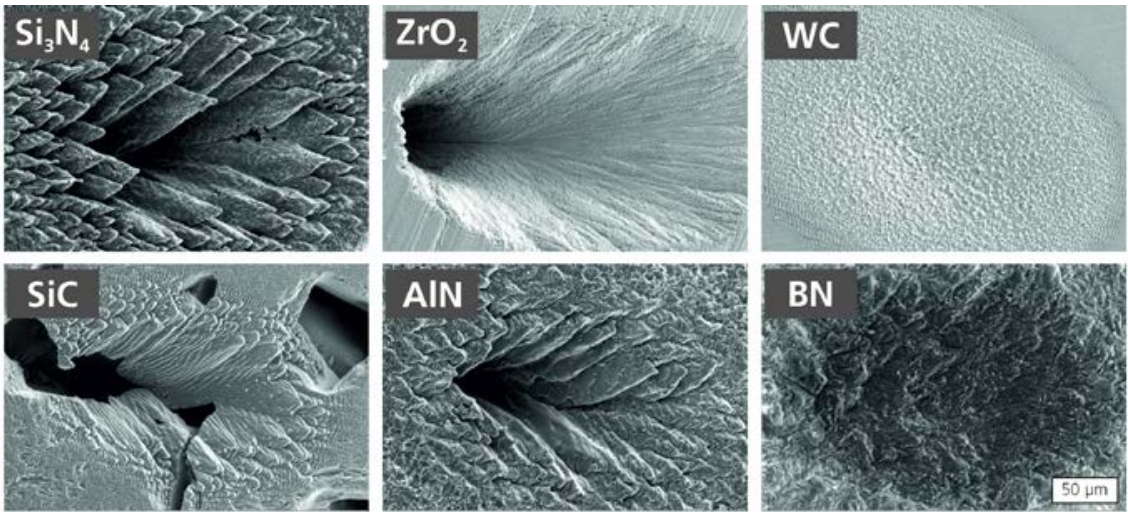

Figure 8: SEM micrographs of ablation spots after $30 \mathrm{k}$ shot irradiations $\left(1064 \mathrm{~nm}, 2.7 \mathrm{~J} / \mathrm{cm}^{2}\right)$.

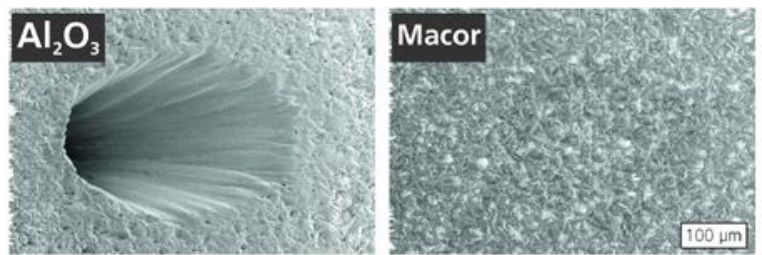

Figure 9: Comparison of ablation spots on $\mathrm{Al}_{2} \mathrm{O}_{3}$ and Macor (1064 nm, $15.5 \mathrm{~J} / \mathrm{cm}^{2}, 1.1 \times 10^{6}$ shots) 

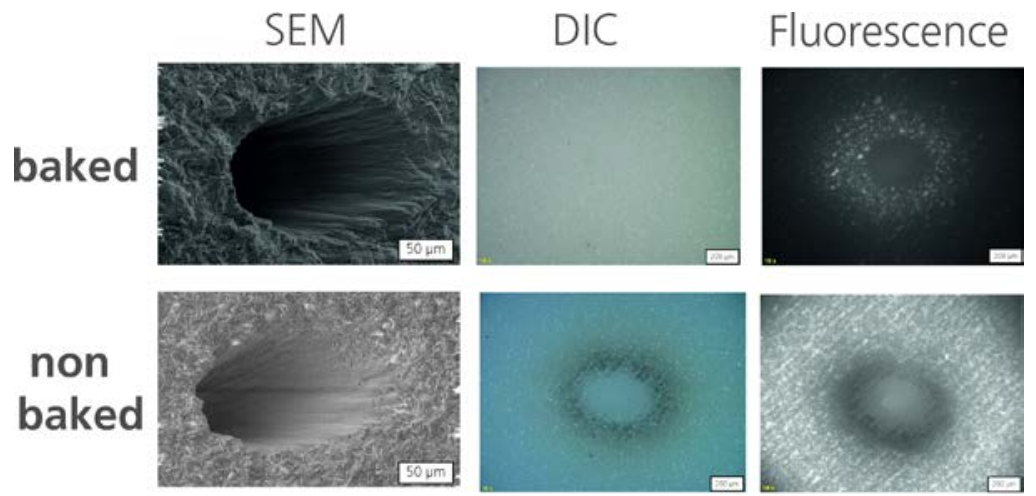

Figure 10: Influence of bake out $\left(500^{\circ} \mathrm{C}, 4 \mathrm{~h}, 1000\right.$ mbar air) on ablation of Macor sample. DIC and fluorescence microscopy micrographs were taken with 4 times lower magnification than SEM pictures.

\subsection{Particle emission}

After the performance of the tests described in 2.2, the corresponding witness optical samples were inspected using WLIM, transmission mapping and bright-field microscopy. Analysis of these results showed no clear evidence of transmission loss or deposits in any of the tests with the ceramic samples. But after each test, some new particles were found on the witness samples. Looking at their size, quantity and position on the surface, it was assumed that they do not originate from the ceramic sample but are due to the handling of the substrate when moving it from the test set-up to the different instruments used for inspection. However, as a safety check the SEM is used to inspect some of these particles and check their element composition by EDX for the tests performed with fluence in the range of the ablation threshold. As indicated above, the composition of the witness sample is $\mathrm{SiO}_{2}$, and that is the background which the EDX spectra show.

Various randomly selected particles were analysed and showed mainly carbon and, in lower concentration, a mix of some other elements (F, Na) incrusted in the carbon. None of these other elements were found on a particle directly deposed on the surface. Extremely small levels of aluminium were found in several of the particles analysed, independently of whether the ceramic sample under tests was composed of $\mathrm{Al}$ or not. It is concluded, that under the presented test configuration no redeposition of particles on the optical witness sample occurred.

\section{SUMMARY}

In this work, the determination of ablation thresholds for ceramic materials and pulsed laser irradiations at 355 and 1064 $\mathrm{nm}$ under vacuum conditions is reported. It was found that Macor has higher threshold values than standard ceramic materials, especially for $1064 \mathrm{~nm}$ irradiations. Long term irradiations with $10^{6}$ shots and a fluence $10 \%$ below ablation thresholds showed no detectable surface change. In case of Macor, it was demonstrated, that bakeout $\left(500^{\circ} \mathrm{C}, 4 \mathrm{~h}\right.$, ambient air) reduced the amount of organic residuals on the surface. In $355 \mathrm{~nm}$ irradiation tests with Macor, WC, BN, AlN, and $\mathrm{Al}_{2} \mathrm{O}_{3}$ at peak fluence in the range of the ablation thresholds no deposition of particles was found on an optical sample near to the target. 


\section{ACKNOWLEDGEMENT}

The authors wish to thank F. Hadinger (DLR Stuttgart) for his support in performing the ablation tests and G.

Taube (DLR Stuttgart) for numerous SEM inspections.

\section{REFERENCES}

[1] M. Endemann, P. Dubock, P. Ingmann, R. Wimmer, D. Morancais, D. Demuth, "The ADM-Aeolus Mission the first wind-lidar in space," Proceedings of 22nd ILRC (International Laser Radar Conference), Matera, Italy, July 12-16, 2004, ESA SP-561, Vol. II, pp. 953-956

[2] W. Riede, P. Allenspacher, H. Schroeder, P. Mahnke, G. Paunescu, D. Wernham, "Aspects of laser optics qualification for space applications", Proc. of SPIE Vol. 7504, (2009), 75040T-1

[3] P. Allenspacher, W. Riede, and D.Wernham, "Vacuum laser damage test bench", Proc. SPIE 5991, 599128-5, 2005. doi:10.1117/12.638550

[4] www.webelements.com 